\title{
O SISU E A ESCOLHA PELAS LICENCIATURAS DA UNIVERSIDADE FEDERAL DE VIÇOSA
}

(D) THAINARA CRISTINA DE CASTRO ARIOVALDO'

(i) CLÁUDIO MARQUES MARTINS NOGUEIRA"

I Universidade Federal de Minas Gerais (UFMG), Belo Horizonte - MG, Brasil thainaracastro_@hotmail.com

II Universidade Federal de Minas Gerais (UFMG), Belo Horizonte - MG, Brasil. cmmn@uol.com.br

\section{RESUMO}

O objetivo deste trabalho é analisar como o Sistema de Seleção Unificada (Sisu) interferiu na escolha pelos cursos superiores na Universidade Federal de Viçosa, examinando principalmente as licenciaturas que tiveram maior aumento na relação candidato por vaga após a implementação desse novo mecanismo de seleção. Foram analisados, inicialmente, dados da instituição sobre a concorrência, a seletividade e a ocupação das vagas de todos os cursos do campus Viçosa-MG e, em seguida, dados recolhidos por meio da aplicação de questionários aos alunos das licenciaturas. Os resultados demonstram que o Sisu influencia as escolhas dos estudantes, tornando-as mais estratégicas, e que as desigualdades sociais e escolares continuam delimitando as escolhas que são possíveis para cada candidato.

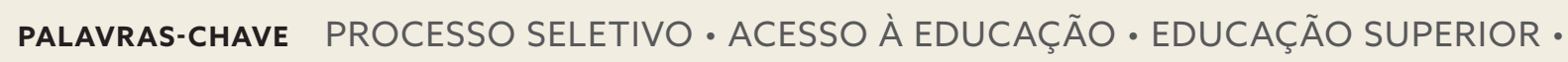
LICENCIATURA. 


\section{EL SISU Y LA ELECCIÓN DE LAS LICENCIATURAS DE LA UNIVERSIDADE FEDERAL DE VIÇOSA}

\section{RESUMEN}

El objetivo de este trabajo es analizar cómo el Sistema de Selección Unificada (Sisu) interfirió en la elección de los cursos superiores en la Universidad Federal de Viçosa, examinando sobre todo las licenciaturas que tuvieron mayor aumento en la relación candidato por plaza después de la implementación de este nuevo mecanismo de selección. Inicialmente, se analizaron datos de la institución sobre la competencia, la selectividad y la ocupación de las plazas de todos los cursos del campus Viçosa-MG, y luego los datos recogidos por medio de la aplicación de cuestionarios a los alumnos de las licenciaturas. Los resultados demuestran que el Sisu influencia las elecciones de los estudiantes y las hace más estratégicas, y también que las desigualdades sociales y escolares siguen delimitando las elecciones posibles para cada candidato.

PALABRAS CLAVE PROCESO DE SELECCIÓN • ACCESO A LA EDUCACIÓN • EDUCACIÓN SUPERIOR • LICENCIATURA.

\section{SISU AND THE CHOICE OF DEGREE PROGRAMS AT THE UNIVERSIDADE FEDERAL DE VIÇOSA}

\section{ABSTRACT}

The objective of this study is to analyze how the Sistema de Seleção Unificada (Unified Selection System - Sisu) affected the choice of higher education programs at the Universidade Federal de Viçosa, mainly examining the degree programs that had the greatest increase in the candidate to vacancy ratios, after the implementation of this new selection mechanism. Initially, data from the institution on competition, selectivity, and vacancy occupation of all the programs at the Viçosa, MG campus were analyzed, and then the data collected by means of questionnaires answered by students of the degree programs. The results demonstrate that the Sisu influences students' choices, making them more strategic, and that social and educational inequalities continue to delimit the choices that are possible for each candidate.

KEYWORDS SELECTIVE PROCESS • ACCESS TO EDUCATION • HIGHER EDUCATION • DEGREE PROGRAMS. 


\section{INTRODUÇÃO}

No Brasil, a emergência de estudos e pesquisas sobre o ensino superior tem uma relação direta com as transformações que esse nível de ensino viveu durante as duas últimas décadas. Nesse período, ocorreram a expansão acentuada do número de matrículas nas redes privada e pública, a interiorização da oferta, a implementação de políticas de ação afirmativa e a criação, pelo governo federal, do Sistema de Seleção Unificada, o Sisu.

Em relação ao Sisu, sua criação foi justificada tendo em vista os objetivos de democratizar o acesso, estimular a mobilidade geográfica dos estudantes e reduzir a ineficiência observada na alocação das vagas das instituições públicas de ensino superior. Desde sua implantação, em 2010, o Sisu apresentou uma crescente adesão por parte das instituições de educação superior, as quais passaram a utilizá-lo de forma concomitante ${ }^{1}$ ou em substituição ao vestibular tradicional. Esse crescimento das instituições participantes se intensificou a partir da implementação da Portaria n. 21, de 5 de dezembro de $2012^{2}$ (BRASIL, 2012b), quando instituições tradicionais - como a Universidade Federal de Minas Gerais (UFMG) - aderiram ao sistema. Para a primeira edição de 2019, como consta no site do Sisu, 129 instituições disponibilizaram vagas na plataforma.

Além da centralização, há outras importantes diferenças entre o novo mecanismo de seleção e o vestibular tradicional. Nesse último, há um processo de autosseleção bastante claro e que ocorre antecipadamente: os candidatos decidem com antecedência prestar o vestibular para um ou alguns poucos cursos que julgam adequados ao seu perfil social, econômico e escolar e descartam, assim, indiretamente, todas as outras possibilidades. Cabe notar que as chances de aprovação nos diferentes cursos são calculadas pelos candidatos com base numa estimativa bastante imprecisa sobre qual será sua nota nos exames escolhidos e de qual será a nota necessária para passar naquele curso naquele ano. Dada a incerteza sobre as chances reais de aprovação, os indivíduos são obrigados a reduzir antecipadamente seu nível de aspiração, o grau de ambição ou de ousadia de suas apostas como forma de diminuir os riscos de uma não aprovação.

O Sisu não elimina as incertezas quanto à aprovação, mas as reduz, já que o candidato realiza sua escolha de curso tendo acesso à sua própria nota, obtida no Exame Nacional do Ensino Médio (Enem) ${ }^{3}$ do ano anterior, além de poder testar essa nota em diversos cursos, em simulações diárias na plataforma durante o período de inscrições. A tomada de decisão é feita, portanto, com muito mais informação.

1 Algumas instituições optaram não por substituir o vestibular diretamente, mas destinar parte das vagas ofertadas ao Sisu. Esse foi o caso da Universidade Federal de Viçosa (UFV).

2 Dispõe sobre o Sisu.

3 Pode fazer a inscrição no Sisu o estudante que participou do Enem do ano anterior e obteve nota na redação diferente de 0 . 
Isso estimula que o candidato ajuste suas escolhas de forma mais precisa, segura e racional às opções em que prevê ser realmente aprovado. A autosseleção que se fazia antecipadamente e com base em informações imprecisas passa a ser feita no momento da inscrição, por meio de um ajuste racional às possibilidades que o sistema indica serem objetivamente viáveis.

Na UFV, o Sisu foi implementado a partir de 2011. Na ocasião, dividiu espaço com o vestibular e com o Programa de Avaliação Seriada para Ingresso no Ensino Superior (Pases) - tradicional seleção trienal da instituição ${ }^{4}$-, ofertando $20 \%$ das vagas. A partir de 2012, o vestibular foi extinto na instituição, e a oferta pelo Sisu passou a ser de $80 \%$. Manteve-se, ainda, o Pases, ofertando os $20 \%$ das vagas restantes. O ano de 2015 marcou a última edição do Pases, e a seleção para as vagas da UFV para 2016 se deu 100\% pelo Sisu.

No campus sede da instituição, localizado na cidade de Viçosa, no estado de Minas Gerais (MG), são oferecidos 45 cursos, dentre os quais 16 são de licenciatura ou que abrem a possibilidade para licenciatura5; é principalmente sobre a influência do Sisu no processo de escolha dos estudantes por esses cursos que a pesquisa que deu origem a este trabalho se pautou. Mesmo num cenário em que a docência se mostra nacionalmente uma opção pouco atrativa (GATTI; SOARES; SOUZA, 2010; LOUZANO et al., 2010; DINIZ-PEREIRA, 2011; NOGUEIRA; FLONTINO, 2014; BAUER; CASSETTARI; OLIVEIRA, 2017), observa-se que as licenciaturas do campus de Viçosa da UFV tiveram crescente procura nos processos seletivos a partir da implementação do Sisu: dos 15 cursos que mais tiveram a relação candidato por vaga (concorrência) aumentada desde a implementação do Sisu, 11 são licenciaturas ou cursos que abrem possibilidade para docência.

Inspirados nos trabalhos de Abreu e Carvalho (2014), Almeida et al. (2016) e Nogueira et al. (2017), que descrevem o Sisu como um jogo de ajustamento feito pelos candidatos entre vagas e instituições do ensino superior de todo território nacional e as possibilidades de aprovação, a hipótese deste trabalho é a de que a crescente escolha pelas licenciaturas da UFV não indicaria maior valorização da profissão docente, mas sim a escolha estratégica por cursos menos seletivos (com menor nota de corte $^{6}$ ) por parte de candidatos que perceberam, durante o período de inscrição no Sisu, que não teriam chances de aprovação nos cursos que mais queriam.

O Pases foi um programa trienal que consistiu em avaliar os participantes por três vezes consecutivas, uma ao final de cada ano do ensino médio, e, após a terceira avaliação, classificá-los para concorrer a uma das vagas de um dos cursos oferecidos pela UFV no ano imediatamente seguinte à terceira etapa do programa.

5 Cursos com habilitação para bacharelado e licenciatura.

6 É a menor nota para ficar entre os selecionados na modalidade escolhida de um determinado curso, com base no número de vagas e no total de candidatos inscritos. Quanto maior a nota de corte exigida por um curso, mais seletivo ele é, pois selecionará estudantes com maior capital econômico e escolar. 
Para investigação dessa hipótese, realizou-se um estudo afunilado da instituição. Inicialmente, tomamos a UFV (campus Viçosa) como um todo e, por meio de dados concedidos pela Pró-Reitoria de Ensino, analisamos informações referentes às mudanças na concorrência (relação candidatos por vaga), na seletividade (nota de corte) e na ocupação das vagas (percentual de vagas ociosas em cada curso). Os dados institucionais analisados vão de 2010 (um ano antes do início da implementação do Sisu na UFV) a 2015 (ano em que 80\% das vagas da instituição eram ofertadas via Sisu). Com base nesses dados, selecionamos os cinco cursos de licenciatura em que houve maior aumento na concorrência desde a implementação do Sisu na UFV (Educação Infantil, Pedagogia, Licenciatura em Física, Licenciatura em Matemática e Licenciatura em Química). Foram aplicados questionários aos alunos que ingressaram em 2015 nesses cursos.

Este trabalho está dividido em quatro partes, além desta introdução. A primeira discute, de forma mais ampla as possíveis influências do Sisu sobre o processo de escolha pelos cursos e sobre a ocupação das vagas no ensino superior público. Na parte seguinte, são feitas apresentação e análise dos dados institucionais coletados. Na terceira parte, são apresentadas as análises dos dados dos questionários aplicados aos estudantes das licenciaturas que se tornaram mais concorridas. Nessa parte, os estudantes foram divididos em dois grupos: o de alunos que ingressaram, mas não estavam mais nos cursos investigados na época da coleta de dados, e o de alunos que permaneciam nesses cursos quando os questionários foram aplicados. Nas considerações finais, é apresentada a síntese dos resultados obtidos e destacada sua contribuição para entendermos os efeitos do Sisu sobre a escolha dos cursos superiores.

\section{SISU E A ESCOLHA DOS CURSOS DE LICENCIATURA}

Nos últimos 20 anos, o sistema de ensino superior público brasileiro tem sido alvo de políticas destinadas a expandir a qualidade e quantidade de sua atuação. Essas políticas buscaram a democratização do acesso a esse nível de ensino e tem produzido uma modificação progressiva do perfil dos estudantes universitários no Brasil (RISTOFF, 2016). Isso significa que esse nível de ensino, até então reservado a uma pequena elite social e escolar, começou a ser frequentado por alunos provenientes de outros grupos sociais. No entanto, as diferentes categorias sociais se beneficiam desse processo de massificação de formas diferentes, e as desigualdades classicamente identificadas pela sociologia da educação se reconfiguram. Para Dubet (2015, p. 258), a observação dos processos de massificação dos sistemas universitários leva à seguinte "lei" sociológica: a massificação reduz "as desigualdades de acesso, mas acentua as desigualdades internas desses sistemas". 
Uma das desigualdades básicas que caracteriza o sistema de ensino superior, particularmente no Brasil, é justamente a que se dá entre os cursos (NOGUEIRA, 2018; HONORATO; ZUCCARELLI; VIEIRA, 2019). Os candidatos e os alunos dos diferentes cursos se distinguem por seu perfil socioeconômico (renda, nível de formação e tipo de ocupação dos pais, necessidade ou não de trabalhar durante o curso), por seu perfil acadêmico (tipo de escola anteriormente frequentada, nível de desempenho escolar) e por variáveis ditas pessoais (sexo, idade e, às vezes, raça/etnia). Candidatos mais novos e com perfil social e escolar mais elevado tendem a escolher os cursos de maior retorno econômico (remuneração média dos egressos) e simbólico (status social). O inverso seria feito pelos candidatos com perfil social e escolar mais baixo, que optam por cursos menos seletivos e nos quais a permanência é mais viável, especialmente as licenciaturas.

Além de todas as características dos candidatos (socioeconômicas, escolares e pessoais) que balizam suas escolhas pelos diferentes cursos, há a interferência das regras e características dos mecanismos de seleção vigentes em cada momento histórico. Em relação ao Sisu, nota-se que houve um aumento generalizado na demanda pelos cursos após sua implementação. Essa elevação se deu, em grande medida, devido à possibilidade de os candidatos poderem concorrer a vagas de instituições localizadas em todo o território brasileiro sem que seja necessário o deslocamento geográfico.

O aumento da demanda após o Sisu parece ter sido ainda mais intenso nos cursos tradicionalmente menos seletivos, como as licenciaturas. Em suas pesquisas, Gatti, Soares e Souza (2010), Louzano et al. (2010), Diniz-Pereira (2011), Aranha e Souza (2013) e Nogueira e Flontino (2014), entre outros, apontam recorrentemente que os cursos de licenciatura, em geral, são pouco atrativos e acabam sendo frequentados predominantemente por candidatos com perfil social e escolar mais baixo. Recentemente, no entanto, após a implementação do Sisu no contexto nacional, pesquisas demonstraram um aumento na procura não somente por esses cursos, mas por outros igualmente menos seletivos e por instituições interioranas e de menor prestígio social (FLORES, 2013; LUZ, 2013; CZERNIASKI, 2014; GÓMEZ, 2015; RIGO, 2016).

Nossa hipótese é que a elevação observada na concorrência pelos cursos menos seletivos, especialmente as licenciaturas, pode estar associada ao modo de funcionamento do Sisu. Como já mencionamos, o Sisu inverte a lógica do vestibular tradicional, de modo que o candidato realiza a escolha do curso em que irá concorrer depois de obter sua nota no Enem. E as mudanças vão além: a plataforma disponibiliza aos candidatos simulações de sua colocação, o que lhes permitem testar suas notas até que encontrem um curso com maior chance de aprovação. Ou seja, o sistema acaba incentivando os candidatos a ajustarem suas preferências originais ao que 
é objetivamente possível de modo a ser aprovado, mesmo que não se trate do curso ou instituição mais desejados (NOGUEIRA et al., 2017).

O aumento da demanda pelas licenciaturas recentemente observado resultaria, assim, do deslocamento de candidatos que prefeririam outros cursos mais seletivos e que perceberam que só seriam aprovados para os cursos de licenciatura, mais acessíveis. Se essa hipótese estiver correta, a elevação na concorrência após a adoção do Sisu tem que ter ocorrido não só nas licenciaturas, mas no conjunto dos cursos com nota de corte mais baixa. Na pesquisa que serve de base para este artigo, investigamos esse aspecto em relação aos cursos do campus Viçosa da UFV. Os dados discutidos na próxima seção parecem sustentar a nossa hipótese.

Se o aumento da demanda pelas licenciaturas decorre de uma escolha estratégica pelos cursos que se mostraram de ingresso possível dada a nota do Enem, e não por aqueles mais desejados, pode-se esperar também que esteja associada a uma elevação das taxas de evasão e de não matrículas. Como mostra Tinto (1989), a probabilidade de evasão nas instituições de ensino superior está em parte associada às intenções e ao comprometimento do estudante em relação à sua formação. Adaptando-se o raciocínio para a evasão de curso, é razoável esperar que essa seja maior quando o candidato escolheu um curso em função da nota de corte, e não como parte de um projeto de realização pessoal e/ou profissional efetivo. A opção por um curso de ingresso possível em detrimento do curso genuinamente desejado pode se traduzir em evasão logo após o ingresso na universidade, além de elevada proporção de não matrículas após a aprovação (NOGUEIRA et al., 2017).

$\mathrm{Na}$ pesquisa, analisamos inicialmente o vínculo entre aumento da concorrência e evasão, sendo que os resultados serão analisados mais à frente neste artigo. Para aprofundar a investigação, realizamos também, por meio da aplicação de questionários, uma análise comparativa entre os estudantes que entraram e já haviam abandonado seus cursos e os que haviam permanecido até a época da coleta dos dados. Por meio desse instrumento, buscou-se entender como as escolhas dos cursos foram feitas e como podem ter repercutido na permanência ou no abandono desses. Os resultados são apresentados na penúltima parte deste trabalho.

\section{DADOS INSTITUCIONAIS: A RELAÇÃO ENTRE O AUMENTO DA COMPETITIVIDADE E A SELETIVIDADE (NOTA DE CORTE) DOS CURSOS DA UFV}

Há duas variáveis comumente utilizadas para medir a posição relativa dos cursos: a relação candidatos por vaga (número de candidatos por vaga) e a nota de corte (nota mínima para aprovação no processo seletivo). Como aponta Branco et al. (2016, p. 30), quanto maior o número de candidatos por vaga e a pontuação mínima para ingresso, maior o prestígio do curso, do ponto de vista acadêmico, de valorização 
social e em termos de retorno financeiro. De modo geral, as pesquisas sobre os cursos de licenciatura vinham demonstrando que esses cursos apresentavam baixa relação candidato por vaga e demandavam baixa pontuação para o ingresso. No entanto, o Sisu, articulado à Lei de Cotas, ${ }^{7}$ tem modificado essa situação, pois esses cursos apresentaram, a partir da implementação dessas políticas, aumento considerável na relação candidatos por vaga.

Acreditamos que, se a hipótese de que o Sisu está incentivando a escolha estratégica pelos cursos da UFV for verdadeira, os cursos com maior aumento na concorrência seriam também os que apresentam notas de corte mais baixas, ou seja, os que se mostrariam mais acessíveis para quem não conseguiria ingressar em cursos mais seletivos. Como já foi dito, o campus analisado oferta vagas em 45 cursos de graduação. Para facilitar a verificação de nossa hipótese, separamos os 15 cursos cuja relação candidatos por vaga teve maior aumento percentual e os 15 em que esse aumento foi menos expressivo ou em que houve decréscimo. Em seguida, relacionamos as notas de corte de 2015 desses dois grupos de cursos, conforme mostra a Tabelas 1 e a Tabela 2.

7 Lei n. 12.711, de 29 de agosto de 2012 (BRASIL, 2012a), que estabelece que "as instituições federais de educação superior vinculadas ao Ministério da Educação reservarão, em cada concurso seletivo para ingresso nos cursos de graduação, por curso e turno, no mínimo 50\% (cinquenta por cento) de suas vagas para estudantes que tenham cursado integralmente o ensino médio em escolas públicas" (Art. $1^{\circ}$ ) e que "cada instituição federal de ensino superior, as vagas serão preenchidas, por curso e turno, por autodeclarados pretos, pardos e indígenas e por pessoas com deficiência, nos termos da legislação, em proporção ao total de vagas no mínimo igual à proporção respectiva de pretos, pardos, indígenas e pessoas com deficiência na população da unidade da Federação onde está instalada a instituição" (Art. $3^{\circ}$ ). 
TABELA 1 - Notas de corte de 2015 dos 15 cursos da UFV que apresentaram as maiores porcentagens de crescimento da relação candidatos por vaga

\begin{tabular}{|c|c|c|c|c|}
\hline \multirow[t]{2}{*}{ ORDEM } & \multirow[t]{2}{*}{ CURSOS } & $\begin{array}{l}\text { NÚMERO DE } \\
\text { CANDIDATOS } \\
\text { POR VAGA }\end{array}$ & $\begin{array}{c}\text { PORCENTAGEM DE } \\
\text { CRESCIMENTO DA } \\
\text { RELAÇÃO CANDIDATOS } \\
\text { POR VAGA }\end{array}$ & \multirow[t]{2}{*}{$\begin{array}{c}\text { NOTAS DE } \\
\text { CORTE DE } 2015\end{array}$} \\
\hline & & 2015 & 2010 PARA 2015 & \\
\hline 1 & Licenciatura em Matemática & 11,9 & $1.055,3$ & 618,6 \\
\hline 2 & Educação Infantil & 28,0 & 976,9 & 572,3 \\
\hline 3 & Dança & 23,9 & 895,8 & 602,3 \\
\hline 4 & Economia Doméstica & 17,5 & 888,7 & 593,8 \\
\hline 5 & Licenciatura em Física & 8,5 & 844,4 & 618,5 \\
\hline 6 & Cooperativismo & 13,5 & 581,8 & 604,3 \\
\hline 7 & Licenciatura em Química & 10,6 & 562,5 & 619,9 \\
\hline 8 & Pedagogia & 26,0 & 537,3 & 604,9 \\
\hline 9 & Educação Física & 33,7 & 525,2 & 624,6 \\
\hline 10 & Letras & 12,4 & 427,7 & 616,5 \\
\hline 11 & Licenciatura em Ciências Biológicas & 19,1 & 398,7 & 627,5 \\
\hline 12 & Ciências Contábeis & 25,3 & 343,9 & 639,3 \\
\hline 13 & Ciências Sociais & 12,9 & 318,8 & 614,7 \\
\hline 14 & Matemática & 8,2 & 276,1 & 626,2 \\
\hline 15 & Arquitetura e Urbanismo & 49,9 & 139,6 & 681,5 \\
\hline
\end{tabular}

Fonte: Elaborado pelos autores a partir dos dados fornecidos pela Pró-Reitoria de Ensino da UFV.

TABELA 2 - Notas de corte de 2015 dos 15 cursos da UFV que apresentaram as menores porcentagens de crescimento da relação candidatos por vaga

\begin{tabular}{c|l|c|c|c}
\hline \multirow{2}{*}{ ORDEM } & \multicolumn{1}{|c|}{ CURSOS } & $\begin{array}{c}\text { NÚMERO DE } \\
\text { CANDIDATOS } \\
\text { POR VAGA }\end{array}$ & $\begin{array}{c}\text { PORCENTAGEM DE } \\
\text { CRESCIMENTO DA } \\
\text { RELAÇO CANDIDATOS } \\
\text { POR VAGA }\end{array}$ & $\begin{array}{c}\text { NOTAS DE } \\
\text { CORTE DE 2015 }\end{array}$ \\
\cline { 2 - 4 } & & 2015 & 2010 PARA 2015 & \\
\hline 1 & Engenharia Florestal & 12,0 & 47,8 & 650,8 \\
\hline 2 & Ciências Econômicas - Economia & 9,3 & 40,5 & 652,5 \\
\hline 3 & Engenharia Agrícola e Ambiental & 11,4 & 40,2 & 656,2 \\
\hline 4 & Ciência da Computação & 16,6 & 34,6 & 662,5 \\
\hline 5 & Engenharia de Alimentos & 10,5 & 33,4 & 659,2 \\
\hline 7 & Direito & 45,8 & 27,3 & 691,9 \\
\hline 8 & Bioquímica & 14,8 & 26,7 & 667,7 \\
\hline 9 & Engenharia Civil & 27,6 & 20,1 & 700,0 \\
\hline 10 & Engenharia Elétrica & 15,5 & 9,9 & 645,5 \\
\hline 11 & Engenharia Mecânica & 15,0 & 5,0 & 685,3 \\
\hline 12 & Engenharia de Produção & 19,3 & $-9,7$ & 692,7 \\
\hline 13 & Engenharia Ambiental & 16,0 & $-19,6$ & 686,0 \\
\hline 14 & Engenharia Química & 13,4 & $-29,8$ & 662,6 \\
\hline 15 & Medicina & 18,4 & $-34,4$ & 709,4 \\
\hline
\end{tabular}

Fonte: Elaborado pelos autores a partir dos dados fornecidos pela Pró-Reitoria de Ensino da UFV. 
Quando confrontamos os percentuais de crescimento da relação candidatos por vaga, após a adoção do Sisu pela UFV com as notas de corte dos cursos, verificamos que o aumento da concorrência está mais associado aos cursos cujas notas mínimas para ingresso são as menores da instituição. Entre esses cursos, dez são de licenciatura. Como demonstram as tabelas 1 e 2, o curso de Educação Infantil teve a maior relação candidatos por vaga entre as licenciaturas em 2015, e sua nota para ingresso foi a menor desse ano na instituição. De modo semelhante, o curso de Economia Doméstica, que apresentou relevante aumento da demanda, obteve em 2015 a segunda menor nota de corte da instituição.

Por outro lado, entre os cursos em que houve menor elevação na relação candidatos por vaga e até decréscimo no período de 2010 a 2015, observamos as graduações mais seletivas da instituição, ou seja, aquelas que exigem as maiores notas de corte para acesso. Desse segundo grupo não faz parte nenhuma das licenciaturas da instituição.

Esses dados reforçam nossa hipótese de que cursos menos seletivos e de baixo prestígio social sofreram maior impacto do Sisu ao se tornarem alvo das estratégias dos candidatos para acederem ao ensino superior no curso que se mostra de ingresso possível, não necessariamente o mais desejado. Notamos que houve aumento da concorrência, indicada pela relação candidatos por vaga, mas não da seletividade nesses cursos, pois suas notas de corte permanecem entre as mais baixas da instituição.

Conforme já anunciamos, tínhamos também a hipótese de que a elevação da concorrência deveria estar associada ao aumento da evasão, visto que parte dos estudantes teria escolhido esses cursos apenas por serem mais acessíveis. Os candidatos entrariam, mas não permaneceriam nesses cursos justamente por não possuírem interesse genuíno por eles. Por isso, analisamos a relação entre o aumento da concorrência e os percentuais de evasão, conforme detalhamos na seção seguinte.

\section{DADOS INSTITUCIONAIS: A RELAÇÃO ENTRE AUMENTO DA CONCORRÊNCIA E EVASÃO NA UFV}

Para verificar nossas hipóteses, observamos os dados sobre evasão referentes a 2010 e 2015. Tomamos os dados de 2010 porque se trata do ano anterior ao primeiro processo seletivo via Sisu na UFV. Todos os alunos que evadiram nesse ano ingressaram na instituição em anos anteriores por meio de outros métodos de seleção. Já o ano de 2015 foi escolhido por dois motivos. O primeiro e principal, como aponta a literatura sobre evasão, diz respeito ao fato de os estudantes tenderem a evadir mais nos primeiros anos dos cursos. Assim, como os dados foram colhidos entre o ano 2016 e 2017, optamos por ingressantes de 2015 que já haviam passado pela fase inicial de 
suas graduações. O segundo motivo se refere à porcentagem de ingressantes via Sisu na UFV, que já chegava, nesse ano, a 80\% do total das vagas disponibilizadas.

Para os cálculos realizados nesta seção, consideramos a definição de Almeida et al. (2016, p. 10), em que se compreende como evadido do curso tanto aquele aluno que desistiu (abandonou sem formalizar o desligamento na instituição) quanto aquele que solicitou formalmente o seu desligamento. Assim, para chegarmos aos percentuais apresentados, foram adicionados os números de alunos que abandonaram, desligaram e mudaram de curso.

Para facilitar a análise dos percentuais de evasão dos cursos, criamos, segundo os mesmos critérios da seção anterior, dois grupos. O primeiro diz respeito aos 15 cursos em que mais houve crescimento na relação candidatos por vaga entre os anos de 2010 e 2015, dando origem à Tabela 3, e o segundo grupo se refere aos cursos com menor crescimento ou decréscimo na concorrência, dando origem à Tabela 4.

TABELA 3 - Evasão em 15 cursos da UFV que tiveram as maiores porcentagens de crescimento da relação candidatos por vaga de 2010 para 2015

\begin{tabular}{l|c|c|c|c|c}
\hline \multirow{2}{*}{ CURSOS } & \multicolumn{2}{|c|}{$\begin{array}{c}\text { NÚMERO DE } \\
\text { CANDIDATOS POR } \\
\text { VAGA }\end{array}$} & $\begin{array}{c}\text { PORCENTAGEM DE } \\
\text { CRESCIMENTO DA } \\
\text { RELAÇÃO CANDIDATOS } \\
\text { POR VAGA }\end{array}$ & \multicolumn{2}{c}{ EVASÃO (\%) } \\
\cline { 2 - 6 } & \multicolumn{2}{|c|}{$\begin{array}{c}\text { TOTAL } \\
\text { PRIMEIROS } \\
\text { PERÍODOS }\end{array}$} \\
\cline { 2 - 6 } Licenciatura em Matemática & 1,03 & 11,90 & $1.055,3$ & $\mathbf{2 0 1 0}$ & $\mathbf{2 0 1 5}$ \\
\hline Educação Infantil & 2,60 & 28,00 & 976,9 & 77,5 \\
\hline Dança & 2,40 & 23,90 & 895,8 & 45,0 & 52,5 \\
\hline Economia Doméstica & 1,77 & 17,50 & 888,7 & 30,0 & 25,0 \\
\hline Licenciatura em Física & 0,90 & 8,50 & 844,4 & 43,3 & 90,0 \\
\hline Cooperativismo & 1,98 & 13,50 & 581,8 & 90,5 & 75,0 \\
\hline Licenciatura em Química & 1,60 & 10,60 & 562,5 & 55,0 & 62,5 \\
\hline Pedagogia & 4,08 & 26,00 & 537,3 & 88,1 & 47,5 \\
\hline Educação Física & 5,39 & 33,70 & 525,2 & 13,6 & 13,3 \\
\hline Letras & 2,35 & 12,40 & 427,7 & 15,7 & 18,6 \\
\hline Licenciatura em Ciências Biológicas & 3,83 & 19,10 & 398,7 & 35,0 & 21,7 \\
\hline Ciências Contábeis & 5,70 & 25,30 & 343,9 & 57,9 & 40,0 \\
\hline Ciências Sociais & 3,08 & 12,90 & 318,8 & 10,0 & 30,0 \\
\hline Matemática & 2,18 & 8,20 & 276,1 & 33,3 & 43,3 \\
\hline Arquitetura e Urbanismo & 20,83 & 49,90 & 139,6 & 83,3 & 57,5 \\
\hline
\end{tabular}

Fonte: Elaborado pelos autores a partir dos dados fornecidos pela Pró-Reitoria de Ensino da UFV. 
TABELA 4 - Evasão em 15 cursos da UFV que tiveram as menores porcentagens de crescimento ou até redução da relação candidatos por vaga de 2010 para 2015

\begin{tabular}{l|c|c|c|c|c}
\hline \multirow{2}{*}{ CURSOS } & \multicolumn{2}{|c|}{$\begin{array}{c}\text { NÚMERO DE } \\
\text { CANDIDATOS POR } \\
\text { VAGA }\end{array}$} & $\begin{array}{c}\text { PORCENTAGEM DE } \\
\text { CRESCIMENTO DA } \\
\text { RELAÇÃO CANDIDATOS } \\
\text { POR VAGA }\end{array}$ & \multicolumn{2}{c}{ EVASÃO (\%) } \\
\cline { 2 - 6 } & $\mathbf{2 0 1 0}$ & $\mathbf{2 0 1 5}$ & $\mathbf{2 0 1 0}$ PARA 2015 & $\mathbf{2 0 1 0}$ & $\mathbf{2 0 1 5}$ \\
\hline Engenharia Florestal & 8,12 & 12,00 & 47,8 & 25,0 & 30,0 \\
\hline Ciências Econômicas - Economia & 6,62 & 9,30 & 40,5 & 38,0 & 46,0 \\
\hline Engenharia Agrícola e Ambiental & 8,13 & 11,40 & 40,2 & 72,5 & 37,5 \\
\hline Ciência da Computação & 12,33 & 16,60 & 34,6 & 57,5 & 40,0 \\
\hline Engenharia de Alimentos & 7,87 & 10,50 & 33,4 & 26,7 & 28,3 \\
\hline Direito & 35,97 & 45,80 & 27,3 & 15,0 & 23,3 \\
\hline Bioquímica & 11,68 & 14,80 & 26,7 & 62,5 & 42,5 \\
\hline Engenharia Civil & 22,98 & 27,60 & 20,1 & 11,7 & 30,0 \\
\hline Ciências Biológicas & 14,10 & 15,50 & 9,9 & 24,5 & 22,0 \\
\hline Engenharia Elétrica & 14,28 & 15,00 & 5,0 & 35,0 & 47,5 \\
\hline Engenharia Mecânica & 21,38 & 19,30 & $-9,7$ & 25,6 & 22,5 \\
\hline Engenharia de Produção & 19,90 & 16,00 & $-19,6$ & 22,5 & 40,0 \\
\hline Engenharia Ambiental & 19,10 & 13,40 & $-29,8$ & 30,0 & 37,5 \\
\hline Engenharia Química & 28,05 & 18,40 & $-34,4$ & 20,0 & 12,5 \\
\hline Medicina & 130,96 & 59,20 & $-54,8$ & 10,0 & 34,0 \\
\hline
\end{tabular}

Fonte: Elaborado pelos autores a partir dos dados fornecidos pela Pró-Reitoria de Ensino da UFV.

Diferentemente do que previa nossa hipótese inicial, não constatamos que a evasão tenha se elevado mais nos 15 cursos que se tornaram mais competitivos após a adoção do Sisu (tabelas 3 e 4). Em 2010, as taxas de evasão nesses cursos já eram mais elevadas do que no segundo grupo, e essa relação se manteve aproximadamente a mesma em 2015. É preciso ressaltar, no entanto, que os dados sobre evasão referentes a 2015 eram parciais, visto que, sobretudo os estudantes que ingressaram no período de 2013 a 2015, ainda não haviam completado o tempo de integralização de suas graduações, podendo, portanto, decidir evadir nos anos seguintes. Tudo indica, desse modo, que a evasão se elevou após o Sisu, mas surpreendentemente isso ocorreu não apenas nos cursos menos seletivos, cuja demanda mais se elevou após a adoção do novo sistema, mas também entre alguns cursos dos mais seletivos, como Medicina.

Nossa hipótese para isso é que estejamos diante de tipos de evasão diferentes. Os estudantes dos cursos menos seletivos e que tivessem maior aumento da demanda após a adoção do Sisu evadiriam predominantemente em busca de outros cursos da mesma instituição, provavelmente de maior prestígio social, aos quais não conseguiram ter acesso ao ingressarem na UFV. Parte desses alunos pode até mesmo ter entrado inicialmente em cursos indicados como segunda opção e terem sido posteriormente chamados para suas primeiras opções. Já os estudantes dos cursos mais 
seletivos e que tiveram menor aumento de demanda após a implantação do Sisu abandonariam a UFV por estarem insatisfeitos com a instituição, não necessariamente com seus cursos.

Para investigar nossa hipótese, buscamos perceber qual tipo de evasão estaria associado a cada perfil de curso (os que tiveram maior aumento na concorrência e os que tiveram menor aumento ou decréscimo). Para isso, os dados sobre a evasão de cada curso foram desagregados, conforme revelam as tabelas 5 e 6.

TABELA 5 - Dados desagregados do número de evadidos dos 15 cursos que apresentaram os maiores acréscimos da relação candidatos por vaga de 2010 para 2015

\begin{tabular}{|c|c|c|c|c|c|c|}
\hline \multirow[b]{2}{*}{ CURSOS } & \multicolumn{3}{|c|}{2010} & \multicolumn{3}{|c|}{2015} \\
\hline & $\begin{array}{l}\text { TOTAL DE } \\
\text { EVADIDOS }\end{array}$ & $\begin{array}{l}\text { MUDANÇA } \\
\text { DE CURSO }\end{array}$ & $\begin{array}{l}\text { ABANDONO + } \\
\text { DESLIGAMENTO }\end{array}$ & $\begin{array}{l}\text { TOTAL DE } \\
\text { EVADIDOS }\end{array}$ & $\begin{array}{l}\text { MUDANÇA } \\
\text { DE CURSO }\end{array}$ & $\begin{array}{l}\text { ABANDONO + } \\
\text { DESLIGAMENTO }\end{array}$ \\
\hline $\begin{array}{l}\text { Licenciatura em } \\
\text { Matemática }\end{array}$ & 13 & 8 & 5 & 31 & 10 & 21 \\
\hline Ed. Infantil & 18 & 5 & 13 & 21 & 14 & 7 \\
\hline Dança & 6 & 1 & 5 & 5 & 4 & 1 \\
\hline Economia Doméstica & 26 & 8 & 18 & 54 & 36 & 18 \\
\hline Licenciatura em Física & 19 & 5 & 14 & 29 & 20 & 9 \\
\hline Cooperativismo & 22 & 9 & 13 & 25 & 17 & 8 \\
\hline Licenciatura em Química & 37 & 15 & 22 & 18 & 10 & 8 \\
\hline Pedagogia & 8 & 1 & 7 & 8 & 1 & 7 \\
\hline Educação Física & 11 & 2 & 9 & 13 & 12 & 1 \\
\hline Letras & 21 & 7 & 14 & 13 & 11 & 2 \\
\hline $\begin{array}{l}\text { Licenciatura em Ciências } \\
\text { Biológicas }\end{array}$ & 22 & 9 & 13 & 16 & 10 & 6 \\
\hline Ciências Contábeis & 4 & 1 & 3 & 12 & 12 & 0 \\
\hline Ciências Sociais & 20 & 4 & 16 & 26 & 1 & 25 \\
\hline Matemática & 40 & 12 & 28 & 23 & 14 & 9 \\
\hline Arquitetura e Urbanismo & 9 & 3 & 5 & 9 & 1 & 8 \\
\hline $\begin{array}{l}\text { MÉDIA DO NÚMERO DE } \\
\text { EVADIDOS }\end{array}$ & 18,4 & 6,0 & 12,3 & 20,2 & 11,5 & 8,7 \\
\hline
\end{tabular}

Fonte: Elaborado pelos autores a partir dos dados fornecidos pela Pró-Reitoria de Ensino. 
TABELA 6 - Dados desagregados do número de evadidos dos 15 cursos que apresentaram os menores acréscimos ou decréscimos da relação candidatos por vaga de 2010 para 2015

\begin{tabular}{|c|c|c|c|c|c|c|}
\hline \multirow[b]{2}{*}{ CURSOS } & \multicolumn{3}{|c|}{2010} & \multicolumn{3}{|c|}{2015} \\
\hline & $\begin{array}{l}\text { TOTAL DE } \\
\text { EVADIDOS }\end{array}$ & $\begin{array}{l}\text { MUDANÇA } \\
\text { DE CURSO }\end{array}$ & $\begin{array}{l}\text { ABANDONO + } \\
\text { DESLIGAMENTO }\end{array}$ & $\begin{array}{l}\text { TOTAL DE } \\
\text { EVADIDOS }\end{array}$ & $\begin{array}{l}\text { MUDANÇA } \\
\text { DE CURSO }\end{array}$ & $\begin{array}{l}\text { ABANDONO + } \\
\text { DESLIGAMENTO }\end{array}$ \\
\hline Eng. Florestal & 15 & 6 & 9 & 18 & 5 & 13 \\
\hline $\begin{array}{l}\text { Ciências Econômicas - } \\
\text { Economia }\end{array}$ & 19 & 4 & 15 & 24 & 5 & 19 \\
\hline $\begin{array}{l}\text { Eng. Agrícola e } \\
\text { Ambiental }\end{array}$ & 29 & 11 & 18 & 31 & 17 & 14 \\
\hline Ciência da Computação & 23 & 7 & 16 & 16 & 2 & 14 \\
\hline Eng. de Alimentos & 16 & 6 & 10 & 17 & 11 & 6 \\
\hline Direito & 8 & 0 & 8 & 14 & 0 & 14 \\
\hline Bioquímica & 25 & 15 & 10 & 17 & 8 & 9 \\
\hline Eng. Civil & 7 & 3 & 4 & 18 & 2 & 16 \\
\hline Ciências Biológicas & 12 & 5 & 7 & 11 & 2 & 9 \\
\hline Eng. Elétrica & 14 & 1 & 13 & 19 & 6 & 13 \\
\hline Eng. Mecânica & 10 & 1 & 9 & 9 & 2 & 7 \\
\hline Eng. de Produção & 9 & 3 & 6 & 16 & 5 & 11 \\
\hline Eng. Ambiental & 12 & 2 & 10 & 15 & 2 & 13 \\
\hline Eng. Química & 8 & 0 & 8 & 5 & 0 & 5 \\
\hline Medicina & 5 & 0 & 5 & 17 & 0 & 17 \\
\hline $\begin{array}{l}\text { MÉDIA DO NÚMERO DE } \\
\text { EVADIDOS }\end{array}$ & 14,1 & 4,3 & 9,9 & 16,5 & 4,5 & 12,0 \\
\hline
\end{tabular}

Fonte: Elaborado pelos autores a partir dos dados fornecidos pela Pró-Reitoria de Ensino da UFV.

Com base nos dados das tabelas 5 e 6, calculamos as médias dos tipos de evasão nos dois grupos de cursos. Nota-se que, enquanto a mudança de curso nas graduações de baixo prestígio social no período de 2010 a 2015 se eleva consideravelmente (indo, em média, de 6,0 para 11,6 estudantes evadidos), nos cursos mais valorizados, a média de estudantes que mudaram de curso é minimamente modificada, passando de 4,3 para 4,5. No que se refere ao abandono e desligamento, nos cursos menos seletivos, o percentual médio decaiu, passando da média de 12,3 para 8,6 estudantes, enquanto nos mais seletivos foi de 9,9 para 12,0.

Esses dados reforçam nossa hipótese de que o aumento da demanda pelos cursos de menor prestígio esteve associado basicamente à estratégia, estimulada pelo Sisu, de ingresso no ensino superior no curso possível, mesmo que não seja o mais desejado. Como se viu, aumentou-se a média daqueles estudantes que ingressaram nos cursos de menor prestígio e depois mudaram para outras graduações na própria instituição.

Por outro lado, os cursos que possuem notas de corte mais altas (como Medicina, Direito, Engenharia Química e Engenharia Civil) apresentam percentuais mais expressivos de abandono e desligamento. Esse dado sugere que esses estudantes já tenham acessado o teto, ou seja, os cursos de maior prestígio da instituição, e que, 
por isso, optam por abandonar ou desligarem-se. Sabendo-se do perfil do alunado que esses cursos atendem (alunos oriundos das camadas médias), é pouco provável que os sujeitos que evadiram da UFV abandonaram/desligaram-se do sistema de ensino superior. Quando se verifica, por exemplo, que, entre os evadidos de Medicina, 100\% abandonaram ou se desligaram, parece razoável concluir que há, nos cursos de alto prestígio, maior probabilidade de estratégias corretivas quanto à instituição.

\section{AS ESCOLHAS PELAS LICENCIATURAS DA UFV}

Após realizarmos a análise dos dados institucionais, levando em consideração a variação da concorrência, da seletividade e dos percentuais de evasão seguida à implementação do Sisu na UFV, realizou-se a segunda fase da investigação, baseada na aplicação dos nossos próprios questionários. Ainda que os dados inicialmente analisados sugiram a comprovação da nossa hipótese de que o Sisu incentive a postura mais estratégica e racional dos estudantes durante o processo de escolha dos cursos, achamos relevante entender como isso acontece de fato e quais os condicionantes sociais e acadêmicos que limitam ou expandem essa possibilidade de "jogar" com o sistema.

Para isso, foram aplicados questionários aos estudantes ingressantes de 2015 das cinco licenciaturas em que o crescimento da concorrência pelas vagas foi mais significativo (Educação Infantil, Licenciatura em Física, Licenciatura em Matemática, Licenciatura em Química e Pedagogia). Foram construídos dois modelos de questionários, sendo o primeiro destinado aos graduandos que ingressaram no referido ano e ainda estavam matriculados nos cursos de licenciatura na fase da coleta dos dados e o segundo direcionado a estudantes dessas turmas que haviam abandonado seus cursos. ${ }^{8}$ Nosso objetivo com essa estratégia foi perceber como as escolhas pelos cursos foram elaboradas.

Os dois questionários continham 41 perguntas fechadas e abertas, as quais foram divididas em blocos. No questionário aplicado aos estudantes que permaneceram no curso de licenciatura, havia um bloco sobre características pessoais e sociodemográfica, um segundo destinado a entender a escolha pelo curso (grau de antecipação da escolha, influência do funcionamento do Sisu na tomada de decisão, cursos indicados durante as simulações, grau de satisfação com o curso e com a instituição) e, por último, as perguntas voltadas para atuação docente (buscou-se perceber influências de pessoas próximas na escolha da licenciatura, desejo de atuação na área educacional, tempo que pretende atuar e se tem o desejo de mudar de curso). No questionário aplicado aos estudantes que não estavam mais matriculados nas licenciaturas, além das perguntas sobre as condições pessoais e sociodemográficas dos sujeitos e a escolha pelo curso de licenciatura, investigamos como foi realizada a decisão de evadir (quando ela foi tomada e se o estudante já ingressou na graduação querendo sair). Por fim, o último bloco de questões desse questionário teve o objetivo de entender a escolha pela graduação atual desses sujeitos (curso/instituição atual, direção da mudança, aproximação com os cursos dos quais evadiram, grau de antecipação da escolha e nível de satisfação com o curso para o qual migrou). 
$\mathrm{Na}$ ocasião de ingresso dos estudantes investigados, eram oferecidas 40 vagas para o curso de Licenciatura em Matemática, 40 para o curso de Educação Infantil, 40 para Licenciatura em Física, 40 para Licenciatura em Química e 60 para Pedagogia, totalizando, assim, 300 estudantes nesses cursos. Dado que 20\% desses ingressaram por meio do Pases, a pesquisa teria o total de 240 sujeitos que entraram via Sisu.

A estratégia de aplicação utilizada nos possibilitou alcançar o número de 85 estudantes que se mantinham matriculados no momento da coleta de dados e 34 estudantes que não estavam mais no curso em que ingressaram em 2015, ou seja, 129 questionários (53,75\% do total de ingressantes). É importante ressaltar que, no que diz respeito aos dados colhidos via questionário, não há pretensão de validade estatística, dado o número relativamente restrito de respondentes. De qualquer forma, é possível perceber variações entre os dois grupos no que diz respeito a forma como as escolhas pela licenciatura foram construídas.

\section{Ingressantes dos cursos de licenciatura da UFV que ainda estavam matriculados}

Ao analisarmos os resultados dos questionários, observamos diferenças entre os perfis dos estudantes que permaneciam nas licenciaturas e daqueles que já haviam evadido. Essas diferenças foram notadas, por exemplo, no que diz respeito à idade (38,9\% dos que permaneceram ingressaram na UFV com 17-18 anos; entre os que abandonaram, essa porcentagem é de 52,9\%), escolaridade da mãe (enquanto $61,8 \%$ das mães dos que evadiram acessaram o ensino superior, completando-o ou não, apenas 14,1\% das mães dos que permanecem chegaram a esse nível de ensino) e origem geográfica (70,6\% dos estudantes que evadiram são de cidades mais distantes de Viçosa; entre os que permaneceram, esse percentual é de 42,3\%). Esses dados sugerem que a decisão de ficar ou partir de cursos menos seletivos não é uma decisão aleatória, mas parece estar associada às possibilidades de escolha dos indivíduos, escolhas essas socialmente condicionadas. ${ }^{9}$

No que se refere à decisão inicial pelo curso de licenciatura, pediu-se aos estudantes que justificassem suas escolhas pelos cursos em que estavam matriculados e em seguida apontassem quando a escolha foi realizada. O objetivo das questões foi entender o grau de antecedência com que a escolha por esses cursos foi feita e o peso da nota do Enem na tomada de decisão.

9 A pesquisa que deu origem a este artigo evidenciou, ainda, variações no perfil dos estudantes entre os cursos. Os dados revelaram que aqueles das graduações da área de exatas têm o perfil socioeconômico mais elevado que os da área de humanas. Trata-se de estudantes mais jovens, com mães mais escolarizadas, detentores de maior renda familiar e originários de cidades mais distantes da Zona da Mata Mineira. Para este artigo, optamos por aprofundar a análise nas questões diretamente referentes aos processos de escolha, por isso apenas apontamos a importância do perfil sociodemográfico para se entender as diferentes tomadas de decisão. 
Ao pensar no funcionamento do Sisu, temos que considerar duas situações possíveis. A primeira, de que o mecanismo pode fazer com que os estudantes rebaixem suas escolhas no momento das simulações ao perceberem que suas notas são insuficientes para acessarem suas opções iniciais. No caso das licenciaturas das ciências exatas, por exemplo, os estudantes revelaram grande interesse em cursos de engenharia. A segunda situação possível é a de que o Sisu pode fazer com que os estudantes decidam por cursos mais seletivos ao notarem que sua nota os coloca entre os possíveis aprovados de determinado curso antes visto como inacessível. Essas situações podem justificar o fato de que, embora alguns estudantes investigados tenham escolhido o curso por afinidade com a profissão, tenham decidido pelo curso no momento da inscrição. Esse caso foi recorrente entre as alunas de Pedagogia, em que muitas estudantes sinalizaram que inicialmente pretendiam realizar o curso de Educação Infantil, cuja seletividade é menor. Seja no primeiro caso ou no segundo, o funcionamento do Sisu auxilia os estudantes a perceberem mais claramente o que é possível.

Assim, nos cursos investigados, a escolha de metade dos estudantes (42 em 84) foi realizada no momento do processo seletivo e devido à nota obtida no Enem, conforme revelam as tabelas 7 e 8 . Esses dados sugerem um grau limitado de segurança na escolha pelo curso de licenciatura em que esses estudantes se matricularam, uma vez que foram escolhidos mais próximos à fase do processo seletivo ou durante ele. Entre os estudantes do curso de Licenciatura em Matemática, por exemplo, $57,1 \%$ tomaram a decisão de fazer o curso durante os dias de simulação, e 42,9\% já haviam escolhido há mais tempo. No entanto, quando perguntados sobre os motivos da escolha, as porcentagens se invertem, $57,1 \%$ escolheram por gostar do curso e da profissão, e 42,9\%, devido à nota do Enem.

TABELA 7 - Grau de antecedência da escolha dos alunos que permanecem no curso de licenciatura

\begin{tabular}{|c|c|c|c|c|c|c|c|c|c|c|}
\hline \multirow{3}{*}{$\begin{array}{l}\text { MOMENTO DE } \\
\text { TOMADA DE DECISÃO } \\
\text { Durante o processo de } \\
\text { inscrição do Sisu }\end{array}$} & \multicolumn{10}{|c|}{ CURSO DE INGRESSO EM 2015} \\
\hline & \multicolumn{2}{|c|}{$\begin{array}{l}\text { EDUCAÇÃO } \\
\text { INFANTIL }\end{array}$} & \multicolumn{2}{|c|}{$\begin{array}{c}\text { LICENCIATURA } \\
\text { EM FÍSICA }\end{array}$} & \multicolumn{2}{|c|}{$\begin{array}{c}\text { LICENCIATURA } \\
\text { EM } \\
\text { MATEMÁTICA }\end{array}$} & \multicolumn{2}{|c|}{$\begin{array}{l}\text { LICENCIATURA } \\
\text { EM QUÍMICA }\end{array}$} & \multicolumn{2}{|c|}{ PEDAGOGIA } \\
\hline & 4 & $50,0 \%$ & 7 & $43,8 \%$ & 4 & $57,1 \%$ & 5 & $35,7 \%$ & 22 & $56,4 \%$ \\
\hline $\begin{array}{l}\text { Tinha decidido há mais } \\
\text { tempo }\end{array}$ & 4 & $50,0 \%$ & 9 & $56,2 \%$ & 3 & $42,9 \%$ & 9 & $64,3 \%$ & 17 & $43,6 \%$ \\
\hline TOTAL & 8 & $100,0 \%$ & 16 & $100,0 \%$ & 7 & $100,0 \%$ & 14 & $100,0 \%$ & 39 & $100,0 \%$ \\
\hline
\end{tabular}

Fonte: Questionário aplicado pelos autores, 2017. 
TABELA 8 - Motivo da escolha pelo curso atual dos alunos que permanecem no curso de licenciatura

\begin{tabular}{|c|c|c|c|c|c|c|c|c|c|c|}
\hline \multirow{3}{*}{$\begin{array}{l}\text { MOTIVO DA ESCOLHA } \\
\text { PELO CURSO ATUAL } \\
\text { Escolheu porque gosta } \\
\text { do curso e da profissão }\end{array}$} & \multicolumn{10}{|c|}{ CURSO DE INGRESSO EM 2015} \\
\hline & \multicolumn{2}{|c|}{$\begin{array}{l}\text { EDUCAÇÃO } \\
\text { INFANTIL }\end{array}$} & \multicolumn{2}{|c|}{$\begin{array}{l}\text { LICENCIATURA } \\
\text { EM FÍSICA }\end{array}$} & \multicolumn{2}{|c|}{$\begin{array}{c}\text { LICENCIATURA } \\
\text { EM } \\
\text { MATEMÁTICA }\end{array}$} & \multicolumn{2}{|c|}{$\begin{array}{l}\text { LICENCIATURA } \\
\text { EM QUÍMICA }\end{array}$} & \multicolumn{2}{|c|}{ PEDAGOGIA } \\
\hline & 4 & $50,0 \%$ & 9 & $56,2 \%$ & 4 & $57,1 \%$ & 8 & $57,1 \%$ & 23 & $57,5 \%$ \\
\hline $\begin{array}{l}\text { Escolheu por não ter } \\
\text { tido nota suficiente } \\
\text { pra ingressar em outro } \\
\text { curso de sua preferência }\end{array}$ & 4 & $50,0 \%$ & 7 & $43,8 \%$ & 3 & $42,9 \%$ & 6 & $42,9 \%$ & 14 & $35,0 \%$ \\
\hline Outra razão & 0 & $0,0 \%$ & 0 & $0,0 \%$ & 0 & $0,0 \%$ & 0 & $0,0 \%$ & 3 & $7,5 \%$ \\
\hline TOTAL & 8 & $100,0 \%$ & 16 & $100,0 \%$ & 7 & $100,0 \%$ & 14 & $100,0 \%$ & 40 & $100,0 \%$ \\
\hline
\end{tabular}

Fonte: Questionário aplicado pela autora na UFV, 2017.

Quando questionados sobre a indicação dos dois cursos no processo seletivo, os estudantes revelaram que a escolha pelo curso de licenciatura em que estavam matriculados foi colocada, frequentemente, como segunda opção. Nota-se, ainda, que a outra opção considerada foi, em muitos casos, cursos cuja concorrência, seletividade e prestígio são relativamente maiores, conforme mostrado na Tabela 9. Essa constatação está de acordo com nossa hipótese, segundo a qual parte dos estudantes que escolheram os cursos aqui analisados o fez por não ter tido condições de ingressar em opções mais seletivas. 
TABELA 9 - Outra opção escolhida durante o processo seletivo do Sisu dos estudantes que permanecem em suas escolhas iniciais

\begin{tabular}{|c|c|c|}
\hline CURSOS & OUTRA OPÇÃO ESCOLHIDA & TOTAL \\
\hline Educação Infantil & História UFV (1), Pedagogia UFV (7) & 8 \\
\hline Licenciatura em Física & $\begin{array}{l}\text { Ciência da Computação UFV (1), Engenharia Civil UFV (1), Engenharia } \\
\text { Mecânica UFV (3), Engenharia Química Ufop }{ }^{10}(1) \text {, Física ABI }{ }^{11} \text { UFV (1), Física } \\
\text { IFMG }^{12} \text { (1), Física UFMG (1), Física Ufop (1), Física UFSCar }{ }^{13}(1) \text {, Licenciatura em } \\
\text { Ciências Biológicas UFV (1), Licenciatura em Física Unifei }{ }^{14} \text { (1), Licenciatura } \\
\text { em Matemática UFV (2), Pedagogia UFV (1) }\end{array}$ & 16 \\
\hline Licenciatura em Matemática & $\begin{array}{l}\text { Arquitetura UFV (2), Matemática ABI UFV (1), Ciência da Computação } \\
\text { UFV (1), Engenharia Civil UTFPR }{ }^{15} \text { (1), Engenharia Florestal UFV (1), } \\
\text { Engenharia Mecânica UFV (1) }\end{array}$ & 7 \\
\hline Licenciatura em Química & $\begin{array}{l}\text { Química ABI UFV (4), Bioquímica UFV (1), Engenharia de Alimentos UFV (1), } \\
\text { Licenciatura em Ciências Biológicas (1), Licenciatura em Química UFMG (3), } \\
\text { Licenciatura em Química UFJF'16 (2), Pedagogia UFV (1), Secretariado } \\
\text { Executivo Trilíngue (1) }\end{array}$ & 14 \\
\hline Pedagogia & $\begin{array}{l}\text { Administração UFV (6), Nutrição UFV (4), Agronomia UFV (1), Arquitetura } \\
\text { UFV (1), Ciências Contábeis UFV (3), Educação Física UFV (1), Educação } \\
\text { Infantil UFV (7), Enfermagem UFV (1), Geografia UFV (2), História UFV (3), } \\
\text { Ciência e Tecnologia de Laticínio UFV (1), Letras UFV (2), Letras Ufla (1), } \\
\text { Pedagogia UFJF (1), Pedagogia Ufop (2), Psicologia UFSJ77 (1), Zootecnia } \\
\text { UFV (1), Nenhum (2) }\end{array}$ & 40 \\
\hline
\end{tabular}

Fonte: Questionário aplicado pelos autores, 2017.

Por meio da aplicação do questionário, também buscamos perceber o interesse por diferentes áreas da educação por parte desses estudantes. Nota-se que quase metade dos respondentes dos cinco cursos aqui analisados não pretendia atuar na educação básica, o que é, sem dúvida, preocupante, se considerarmos que são cursos de licenciatura. Esse descompasso entre a modalidade dos cursos que estão fazendo e os projetos profissionais que almejam é um indicativo a mais de que uma parte relevante dos alunos não escolheu os cursos que mais queria, mas aqueles em que era possível ingressar.

10 Universidade Federal de Ouro Preto.

11 Área Básica de Ingresso.

12 Instituto Federal de Educação, Ciência e Tecnologia de Minas Gerais.

13 Universidade Federal de São Carlos.

14 Universidade Federal de Itajubá.

15 Universidade Tecnológica Federal do Paraná.

16 Universidade Federal de Juiz de Fora.

17 Universidade Federal de São João del-Rei. 
TABELA 10 - Desejo de atuação na área educacional pelos alunos que permanecem nos cursos

\begin{tabular}{|c|c|c|c|c|c|c|c|}
\hline \multicolumn{2}{|c|}{$\begin{array}{l}\text { DESEJO DE } \\
\text { ATUAÇÃO }\end{array}$} & $\begin{array}{l}\text { EDUCAÇÃO } \\
\text { INFANTIL }\end{array}$ & $\begin{array}{c}\text { LICENCIATURA } \\
\text { EM FÍSICA }\end{array}$ & $\begin{array}{c}\text { LICENCIATURA } \\
\text { EM } \\
\text { MATEMÁTICA }\end{array}$ & $\begin{array}{l}\text { LICENCIATURA } \\
\text { EM QUÍMICA }\end{array}$ & PEDAGOGIA & TOTAL \\
\hline \multirow{4}{*}{$\begin{array}{l}\text { Educação } \\
\text { Básica }\end{array}$} & \multirow{2}{*}{ Sim } & 7 & 7 & 0 & 8 & 20 & 42 \\
\hline & & $87,5 \%$ & $43,8 \%$ & $0,0 \%$ & $57,1 \%$ & $50,0 \%$ & $49,4 \%$ \\
\hline & \multirow{2}{*}{ Não } & 1 & 9 & 7 & 6 & 20 & 43 \\
\hline & & $12,5 \%$ & $56,2 \%$ & $100,0 \%$ & $42,9 \%$ & $50,0 \%$ & $50,6 \%$ \\
\hline \multirow{4}{*}{$\begin{array}{l}\text { Gestão } \\
\text { Escolar }\end{array}$} & \multirow{2}{*}{ Sim } & 0 & 0 & 0 & 0 & 5 & 5 \\
\hline & & $0,0 \%$ & $0,0 \%$ & $0,0 \%$ & $0,0 \%$ & $12,5 \%$ & $5,9 \%$ \\
\hline & \multirow{2}{*}{ Não } & 8 & 16 & 7 & 14 & 35 & 80 \\
\hline & & $100,0 \%$ & $100,0 \%$ & $100,0 \%$ & $100,0 \%$ & $87,5 \%$ & $94,1 \%$ \\
\hline \multirow{4}{*}{$\begin{array}{l}\text { Ensino } \\
\text { Superior }\end{array}$} & \multirow{2}{*}{ Sim } & 3 & 6 & 4 & 7 & 14 & 34 \\
\hline & & $37,5 \%$ & $37,5 \%$ & $57,1 \%$ & $50,0 \%$ & $35,0 \%$ & $40,0 \%$ \\
\hline & \multirow{2}{*}{ Não } & 5 & 10 & 3 & 7 & 26 & 51 \\
\hline & & $62,5 \%$ & $62,5 \%$ & $43,9 \%$ & $50,0 \%$ & $65,0 \%$ & $60,0 \%$ \\
\hline \multirow{4}{*}{$\begin{array}{l}\text { Educação } \\
\text { não formal }\end{array}$} & \multirow{2}{*}{ Sim } & 1 & 5 & 0 & 0 & 4 & 10 \\
\hline & & $12,5 \%$ & $31,2 \%$ & $0,0 \%$ & $0,0 \%$ & $10,0 \%$ & $11,8 \%$ \\
\hline & \multirow{2}{*}{ Não } & 7 & 11 & 7 & 14 & 36 & 75 \\
\hline & & $87,5 \%$ & $68,8 \%$ & $100,0 \%$ & $100,0 \%$ & $90 \%$ & $88,8 \%$ \\
\hline
\end{tabular}

Fonte: Questionário aplicado pela autora na UFV, 2017.

Ingressantes dos cursos de licenciatura da UFV em 2015 que já haviam evadido

No caso dos evadidos, é preciso ressaltar o quão difícil foi encontrar sujeitos já sem vínculos institucionais com o curso e/ou com a UFV; por isso, decidimos fazer uso de diferentes instrumentos que as novas tecnologias nos possibilitaram. Para o desenvolvimento desta pesquisa, por exemplo, o uso do Facebook foi fundamental.

Foram aplicados e analisados 34 questionários (cinco para evadidos do curso de Educação Infantil, oito da Licenciatura em Física, seis da Licenciatura em Matemática, nove da Licenciatura em Química e seis da Pedagogia). Procedemos de modo semelhante à análise das informações coletadas com o outro grupo de estudantes, buscando, a princípio, caracterizar o perfil sociodemográfico e, em seguida, os processos pelos quais as estratégias de escolha do curso de graduação foram construídas.

Quanto ao perfil socioeconômico, como mencionado anteriormente, o grupo de estudantes que ingressou nos cursos investigados e evadiu apresenta situação relativamente mais vantajosa do que aquela que caracteriza os que permanecem nesses cursos. Esses também se destacam por serem mais novos e terem uma origem geográfica mais dispersa.

Depois de considerarmos as características sociodemográficas, buscamos entender o processo de escolha pelo curso de licenciatura e por que os investigados 
não se matricularam diretamente nos cursos em que estão atualmente. Por meio da indagação "Se você já estava fazendo o curso de licenciatura no qual ingressou em 2015, por que resolveu se candidatar ao curso em que está agora?”, percebemos que, embora as respostas tenham sido variadas, muitas se relacionavam direta ou indiretamente ao modo de funcionamento do Sisu.

TABELA 11 - Motivo para não ter se matriculado no curso atual diretamente (resposta múltipla)

\begin{tabular}{|c|c|c|c|c|c|}
\hline \multirow[b]{2}{*}{ JUSTIFICATIVAS } & \multicolumn{5}{|c|}{ CURSO DO QUAL EVADIU } \\
\hline & $\begin{array}{l}\text { EDUCAÇÃO } \\
\text { INFANTIL }\end{array}$ & $\begin{array}{l}\text { LICENCIATURA } \\
\text { EM FÍSICA }\end{array}$ & $\begin{array}{l}\text { LICENCIATURA } \\
\text { EM } \\
\text { MATEMÁTICA }\end{array}$ & $\begin{array}{l}\text { LICENCIATURA } \\
\text { EM QUÍMICA }\end{array}$ & PEDAGOGIA \\
\hline $\begin{array}{l}\text { Não passei no processo } \\
\text { seletivo para esse curso em } \\
2015\end{array}$ & $\begin{array}{c}5 \\
100,0 \%\end{array}$ & $\begin{array}{c}6 \\
75,0 \%\end{array}$ & $\begin{array}{c}6 \\
100,0 \%\end{array}$ & $\begin{array}{c}9 \\
100,0 \%\end{array}$ & $\begin{array}{c}4 \\
66,6 \%\end{array}$ \\
\hline $\begin{array}{l}\text { Gosto pela área do outro } \\
\text { curso }\end{array}$ & $\begin{array}{c}5 \\
100,0 \%\end{array}$ & $\begin{array}{c}8 \\
100,0 \%\end{array}$ & $\begin{array}{c}6 \\
100,0 \%\end{array}$ & $\begin{array}{c}9 \\
100,0 \%\end{array}$ & $\begin{array}{c}4 \\
66,6 \%\end{array}$ \\
\hline $\begin{array}{l}\text { Não gostei do curso de } \\
\text { Licenciatura inicial }\end{array}$ & $\begin{array}{c}5 \\
100,0 \%\end{array}$ & $\begin{array}{c}8 \\
100,0 \%\end{array}$ & $\begin{array}{c}3 \\
50,0 \%\end{array}$ & $\begin{array}{c}5 \\
55,5 \%\end{array}$ & $\begin{array}{c}4 \\
66,6 \%\end{array}$ \\
\hline $\begin{array}{l}\text { Dificuldades financeiras } \\
\text { para me manter matriculado }\end{array}$ & $\begin{array}{c}0 \\
0,0 \%\end{array}$ & $\begin{array}{c}2 \\
25,0 \%\end{array}$ & $\begin{array}{c}0 \\
0,0 \%\end{array}$ & $\begin{array}{c}0 \\
0,0 \%\end{array}$ & $\begin{array}{c}0 \\
0,0 \%\end{array}$ \\
\hline Dificuldade do curso & $\begin{array}{c}0 \\
0,0 \%\end{array}$ & $\begin{array}{c}3 \\
37,5 \%\end{array}$ & $\begin{array}{c}3 \\
50,0 \%\end{array}$ & $\begin{array}{c}5 \\
55,5 \%\end{array}$ & $\begin{array}{c}0 \\
0,0 \%\end{array}$ \\
\hline $\begin{array}{l}\text { Era minha primeira opção, } \\
\text { não fui aprovado }\end{array}$ & $\begin{array}{c}5 \\
100,0 \%\end{array}$ & $\begin{array}{c}6 \\
75,0 \%\end{array}$ & $\begin{array}{c}6 \\
100,0 \%\end{array}$ & $\begin{array}{c}9 \\
100,0 \%\end{array}$ & $\begin{array}{c}4 \\
66,6 \%\end{array}$ \\
\hline
\end{tabular}

Fonte: Questionário aplicado pela autora na UFV, 2017.

Assim, entre as respondentes evadidas do curso de Educação Infantil, 100\% sinalizaram não ter se matriculado diretamente por não terem sido aprovadas. $\mathrm{O}$ mesmo ocorreu com os sujeitos que abandonaram a Licenciatura em Matemática e Licenciatura em Química. No curso de Licenciatura em Física, 75\% dos sujeitos também apontaram o fato de não terem sido aprovados. Fica claro, portanto, que predominou, entre os respondentes evadidos, a lógica da escolha do curso possível no momento do processo seletivo.

Outro aspecto a ser considerado é o momento em que esses alunos escolheram os cursos de licenciatura. Observamos, na Tabela 12, que em grande medida esses estudantes ingressaram nas licenciaturas a partir de uma decisão feita preponderantemente durante o período de inscrição e com base em suas notas obtidas no Enem $(82,4 \%)$. 
TABELA 12 - Grau de antecedência da segunda escolha dos alunos que evadiram

\begin{tabular}{|c|c|c|c|c|c|c|}
\hline $\begin{array}{l}\text { QUANDO } \\
\text { ESCOLHEU O } \\
\text { CURSO }\end{array}$ & $\begin{array}{l}\text { EDUCAÇÃO } \\
\text { INFANTIL }\end{array}$ & $\begin{array}{c}\text { LICENCIATURA } \\
\text { EM FÍSICA }\end{array}$ & $\begin{array}{c}\text { LICENCIATURA } \\
\text { EM } \\
\text { MATEMÁTICA }\end{array}$ & $\begin{array}{c}\text { LICENCIATURA } \\
\text { EM QUÍMICA }\end{array}$ & PEDAGOGIA & TOTAL \\
\hline $\begin{array}{l}\text { Durante o } \\
\text { processo de } \\
\text { inscrição do Sisu }\end{array}$ & $\stackrel{5}{100,0 \%}$ & $\begin{array}{c}8 \\
100,0 \%\end{array}$ & $\begin{array}{c}4 \\
33,3 \%\end{array}$ & $\begin{array}{c}9 \\
100,0 \%\end{array}$ & $\begin{array}{c}2 \\
33,3 \%\end{array}$ & $\begin{array}{c}28 \\
82,4 \%\end{array}$ \\
\hline $\begin{array}{l}\text { Tinha decidido há } \\
\text { mais tempo }\end{array}$ & $\begin{array}{c}0 \\
0,0 \%\end{array}$ & $\begin{array}{c}0 \\
0,0 \%\end{array}$ & $\begin{array}{c}2 \\
66,7 \%\end{array}$ & $\begin{array}{c}0 \\
0,0 \%\end{array}$ & $\begin{array}{c}4 \\
66,7 \%\end{array}$ & $\begin{array}{c}6 \\
17,6 \%\end{array}$ \\
\hline
\end{tabular}

Fonte: Questionário aplicado pelos autores, 2017.

Outro indicador de que as escolhas pelas licenciaturas corresponderam a uma adaptação é o fato de em muitos casos se tratar da segunda opção assinalada pelos estudantes no processo seletivo de 2015, aquela em que era permitido matricular-se e continuar concorrendo à primeira opção indicada. Na Tabela 13, podemos perceber que, com exceção do curso de Pedagogia, os demais optaram em grande medida por indicar as graduações de licenciatura das quais evadiram.

TABELA 13 - Estudantes que ingressam nos cursos de licenciatura da UFV e evadiram e a opção por essa licenciatura no Sisu de 2015

\begin{tabular}{|c|c|c|c|c|c|c|c|c|c|c|}
\hline \multirow{3}{*}{$\begin{array}{c}2^{\circ} \text { OPÇÃO } \\
\text { Sim }\end{array}$} & \multicolumn{10}{|c|}{ CURSO DE INGRESSO EM 2015} \\
\hline & \multicolumn{2}{|c|}{$\begin{array}{l}\text { EDUCAÇÃO } \\
\text { INFANTIL }\end{array}$} & \multicolumn{2}{|c|}{$\begin{array}{l}\text { LICENCIATURA } \\
\text { EM FÍSICA }\end{array}$} & \multicolumn{2}{|c|}{$\begin{array}{c}\text { LICENCIATURA } \\
\text { EM } \\
\text { MATEMÁTICA }\end{array}$} & \multicolumn{2}{|c|}{$\begin{array}{l}\text { LICENCIATURA } \\
\text { EM QUÍMICA }\end{array}$} & \multicolumn{2}{|c|}{ PEDAGOGIA } \\
\hline & 4 & $80,0 \%$ & 7 & $87,5 \%$ & 5 & $83,3 \%$ & 6 & $66,6 \%$ & 2 & $33,3 \%$ \\
\hline Não & 1 & $20,0 \%$ & 1 & $12,5 \%$ & 1 & $16,7 \%$ & 3 & $33,3 \%$ & 4 & $66,6 \%$ \\
\hline Total & 5 & $100,0 \%$ & 8 & $100,0 \%$ & 6 & $100,0 \%$ & 9 & $100,0 \%$ & 6 & $100,0 \%$ \\
\hline
\end{tabular}

Fonte: Questionário aplicado pelos autores, 2017.

Por último, vale considerar que muitos dos estudantes que estão matriculados atualmente em outros cursos fizeram a mudança para cursos de maior prestígio (ainda que estejamos tratando de um prestígio relativo), conforme apontado na Tabela 13. 
TABELA 14 - Cursos em que estão matriculados estudantes que evadiram dos cursos de Licenciatura da UFV

\begin{tabular}{l|l|c}
\hline & \multicolumn{1}{|c}{ CURSO EM QUE ESTÁ MATRICULADO ATUALMENTE } & TOTAL \\
\hline Educação Infantil & Pedagogia UFV (4), Letras UFV (1) & 5 \\
\hline Pedagogia & $\begin{array}{l}\text { Pedagogia Unifran } \\
\text { UFV (1) (1), Administração UFV (1), Pedagogia Unopar }{ }^{19} \text { (1), Geografia }\end{array}$ & 4 \\
\hline Licenciatura em Física & $\begin{array}{l}\text { Agronomia UFV (3), Física UFV ABI Diurno (2), Engenharia Civil Univiçosa }{ }^{20}(1), \\
\text { Engenharia Mecânica UFV (1), Engenharia Agrícola e Ambiental UFV (1) }\end{array}$ & 8 \\
\hline $\begin{array}{l}\text { Licenciatura em } \\
\text { Matemática }\end{array}$ & $\begin{array}{l}\text { Ciência da Computação UFV (1), "Cursinho preparatório pré-vestibular para } \\
\text { engenharia" (1), Matemática UFV ABI Diurno (1), Engenharia Civil Fupac² (1), } \\
\text { Engenharia Florestal UFV (1), Ciências Contábeis UFV (1) }\end{array}$ & 6 \\
\hline $\begin{array}{l}\text { Licenciatura em } \\
\text { Química }\end{array}$ & $\begin{array}{l}\text { Enfermagem UFV (2), Química UFV ABI Diurno (2), Engenharia Química UFV (2), } \\
\text { Química Industrial UFMG (1), Engenharia Elétrica UFV (1), Química Tecnológica - } \\
\text { Faculdade Estadual de São João do Manhuaçu (1) }\end{array}$ & 9 \\
\hline
\end{tabular}

Fonte: Questionário aplicado pelos autores, 2017.

\section{CONSIDERAÇÕES FINAIS}

Os resultados desta pesquisa apontam para a influência das regras do Sisu sobre a escolha dos cursos pelos ingressantes da UFV, campus Viçosa. Essa influência foi evidenciada ao traçarmos as características relativas à competitividade, seletividade e ocupação das vagas dos diferentes cursos da instituição. Notamos que cursos tradicionalmente menos seletivos (sobretudo licenciaturas) tornaram-se mais concorridos, mas que esse fato não parece significar maior valorização dessas carreiras, posto que permanecem como cursos com baixas notas de corte no ingresso e com taxas de evasão mais acentuadas. Ao investigar o processo de escolha dos ingressantes das licenciaturas que se tornaram mais concorridas, esse fato se torna mais claro, uma vez que percebemos que foram escolhas influenciadas, em grande medida, pelo funcionamento do processo seletivo.

Acreditamos que uma das regras que mais impactou o processo de construção de estratégias de acesso por parte dos candidatos e na ocupação das vagas é o fato de que o Sisu permitia ao estudante continuar a concorrer aos cursos indicados em primeira opção, mesmo já tendo se matriculado em sua segunda opção. Essa possibilidade estimulava os candidatos a ousarem mais na indicação de sua primeira opção e menos na indicação da segunda. Uma vez aprovados nesta última, aguardavam na lista de espera a chamada para a primeira opção. Caso esta ocorresse, evadiam do curso escolhido estrategicamente em busca de suas preferências genuínas.

\footnotetext{
18 Universidade de Franca.

19 Faculdades Integradas Norte do Paraná.

20 Centro Universitário de Viçosa.

21 Fundação Presidente Antônio Carlos de Ubá.
} 
A Portaria n. 1.117, de 1 de novembro de 2018 (BRASIL, 2018), altera, no entanto, as regras do Sisu a partir da primeira edição do processo seletivo de 2019. A partir desse momento, ficou estabelecido que, caso o estudante seja selecionado na chamada regular em um dos cursos indicados, ele não poderá participar da lista de espera para a outra opção indicada, como ocorria nos anos anteriores. Sendo assim, só é possível que o candidato manifeste o desejo de participar da lista de espera caso não tenha sido aprovado em nenhuma das duas possibilidades indicadas. Mesmo nesse caso, poderá optar pela lista de apenas um dos cursos que havia originalmente indicado.

Embora ainda seja cedo para concluir a respeito, acreditamos que essas medidas possam reduzir o campo de possibilidades de jogadas estratégicas por parte dos candidatos, fazendo com que estes se restrinjam a escolhas mais próximas de suas preferências genuínas. Caso isso ocorra, haverá efeitos positivos para as instituições no que diz respeito à ocupação das vagas, já que poderá diminuir a movimentação dos estudantes e talvez o número de vagas ociosas. Certamente, novas investigações devem ser realizadas para confirmar as consequências dessas novas regras.

\section{REFERÊNCIAS}

ABREU, Luís; CARVALHO, José R. Análise do jogo induzido pelo mecanismo Sisu de alocação de estudantes em universidades. In: ENCONTRO NACIONAL DE ECONOMIA - ANPEC, 42., 2014, Natal. Anais [...]. Natal, 2014.

ALMEIDA, Aléssio Tony Cavalcante de; SIQUEIRA, Liédje Bettizai de Oliveira de; SILVA, Andrea Ferreira da; SOBRAL, Eryka Fernanda Miranda; ROCHA, Evandro Farias. Estratégia safe choice sob menor incerteza e alocação ineficiente no ensino superior brasileiro. In: ENCONTRO REGIONAL DE ECONOMIA, 21., 2016, Fortaleza. Anais [...] Fortaleza, 2016.

ARANHA, Antônia Vitória Soares; SOUZA, João Valdir Alves. As licenciaturas na atualidade: nova crise? Educar em Revista, Curitiba, n. 50, p. 69-86, out./dez. 2013.

BAUER, Adriana; CASSETTARI, Nathalia; OLIVEIRA, Romualdo Portela de. Políticas docentes e qualidade da educação: uma revisão da literatura e indicações de política. Ensaio: Avaliação e Políticas Públicas em Educação, Rio de Janeiro, v. 25, n. 97, p. 943-970, out./dez. 2017.

BRANCO, Amanda Leal Castelo; BONTEMPO, Ginia Cezar; SARAIVA, Ana Claudia Lopes Chequer; AMARAL, Shirlena Campos de Souza. O processo de escolha por um curso superior após a "Lei de Cotas" e o Enem/Sisu: o caso dos cursos de licenciatura da UFV campus Viçosa. Revista Brasileira de Ensino Superior, Passo Fundo, RS, v. 2, n. 1, p. 21-33, 2016.

BRASIL. Lei n. 12.711, de 29 de agosto de 2012. Dispõe sobre o ingresso nas universidades federais e nas instituições federais de ensino técnico de nível médio e dá outras providências. Brasília, DF: Presidência da República, Casa Civil, Subchefia para Assuntos Jurídicos, 2012a. 
BRASIL. Portaria n. 21, de 5 de novembro de 2012. Dispõe sobre o Sistema de Seleção Unificada - Sisu, 2012b. Disponível em: https://sisu.furg.br/images/portaria21mec.pdf. Acesso em: 28 jan. 2019.

BRASIL. Portaria n. 1.117, de 1 de novembro de 2018. Altera a Portaria Normativa MEC n. 18, de 11 de outubro de 2012, e a Portaria Normativa MEC n. 21, de 5 de novembro de 2012, 2018. Disponível em: http://www.in.gov.br/materia/-/asset_publisher/Kujrw0TZC2Mb/content/id/48448738/do1-201811-05-portaria-n-1-117-de-1-de-novembro-de-2018-48448535. Acesso em: 28 jan. 2019.

CZERNIASKI, Lizandra Felippi. Políticas públicas de democratização do ensino superior: um estudo sobre a ocupação das vagas nos cursos de graduação na Universidade Tecnológica Federal do Paraná - Campus Francisco Beltrão. 2014. 111 f. Dissertação (Mestrado em Políticas Públicas). Universidade Estadual de Maringá, Maringá, 2014.

DINIZ-PEREIRA, Júlio E. O ovo e a galinha: a crise da profissão docente e a aparente falta de perspectiva para a educação brasileira. Revista Brasileira de Estudos Pedagógicos, Brasília, DF, v. 92, n. 230, p. 34-54, jan./abr. 2011.

DUBET, François. Qual democratização do ensino superior? Caderno CRH, Salvador, v. 28, n. 74, p. 255-266, ago. 2015.

FLORES, Cézar Augusto da Silva. A escolha do curso superior no sistema de seleção unificada - SiSU: o caso do curso de enfermagem da Universidade Federal de Mato Grosso, Campus Universitário de Sinop. 2013. 181 p. Dissertação (Mestrado em Educação) - Faculdade de Educação, Universidade Federal do Mato Grosso, Cuiabá, 2013.

GATTI, Bernadete; SOARES, Juliana Gomes da Silva; SOUSA, Raimundo Nonato. A atratividade da carreira docente no Brasil. In: Estudos \& pesquisas educacionais. São Paulo: Fundação Victor Civita, 2010, p. 139-210.

GÓMEZ, Magela Reny Fonticiella. Acesso e permanência de alunos de engenharia da UTFPR - Câmpus Medianeira. 2015. 123 f. Dissertação (Mestrado em Educação) - Universidade Estadual Paulista Júlio de Mesquita Filho, Marília, SP, 2015.

HONORATO, Gabriela; ZUCCARELLI, Carolina; VIEIRA, André. Estratificação horizontal nas licenciaturas das instituições federais brasileiras. Revista Contemporânea de Educação, Rio de Janeiro, v. 14, n. 29, jan./abr. 2019.

LOUZANO, Paula; ROCHA, Valéria; MORICONI, Gabriela; OLIVEIRA, Romualdo. Quem quer ser professor? Atratividade, seleção e formação docente no Brasil. Estudos em Avaliação Educacional, São Paulo, v. 21, n. 47, p. 543-568, set./dez. 2010.

LUZ, Jackeline Lourenço Noronha da. O Sistema de Seleção Unificada (Sisu) na Universidade Federal de Mato Grosso - Campus Cuiabá - e a relação com a democratização do acesso. 2013. 186 f. Dissertação (Mestrado em Educação). Universidade Federal do Mato Grosso, Cuiabá, 2013.

NOGUEIRA, Cláudio Marques Martins. Qual acesso ao ensino superior? Colocando a "escolha" dos cursos superiores por parte dos candidatos no centro do debate. In: LAS CASAS, Estevam Barbosa; CUNHA, Dayse Moreira. Educação superior: desafios em perspectivas transdisciplinares. Belo Horizonte: Universidade Federal de Minas Gerais, 2018. p. 21-39.

NOGUEIRA, Cláudio Marques Martins; FLONTINO, Sandra Dantas. A escolha dos cursos de formação de professores e da profissão docente num cenário de desvalorização do magistério: 
os estudantes de licenciatura da Universidade Federal de Minas Gerais. In: PORTUGAL E MELO, Benedita (org.). Entre crise e euforia: práticas e políticas educativas no Brasil e em Portugal. Porto: Universidade do Porto, 2014. p. 35-68.

NOGUEIRA, Cláudio Marques Martins; NONATO, Bréscia França; RIBEIRO, Gustavo Meirelles; FLONTINO, Sandra Regina Dantas. Promessas e limites: o Sisu e sua implementação na Universidade Federal de Minas Gerais. Educação em Revista, Belo Horizonte, v. 33, n. 2, p. 61-90, abr./jun. 2017.

RIGO, Júlia da Silva. Percursos de formação de estudantes de licenciatura noturna na UFV: Enem, Sisu e Evasão. 2016. 136 f. Dissertação (Mestrado em Educação) - Universidade Federal de Viçosa, Viçosa, 2016.

RISTOFF, Dilvo. Democratização do campus - Impacto dos programas de inclusão sobre o perfil da graduação. Cadernos do GEA, Rio de Janeiro, n. 9, p. 1-62, jan./jun. 2016.

TINTO, Vicent. Definir la desercion: una cuestion de perspectiva. Revista de la Educacion Superior, México, v. 18, n. 3, p. 33-51, 1989.

COMO CITAR ESTE ARTIGO:

ARIOVALDO, Thainara Cristina de Castro; NOGUEIRA, Cláudio Marques Martins. O Sisu e a escolha pelas licenciaturas da Universidade Federal de Viçosa. Estudos em Avaliação Educacional, São Paulo, v. 32, p. 1-27, e06763, 2021. DOI: https://doi. org/10.18222/eae.v32.6763

Recebido em: 16 AGOSTO 2019

Aprovado para publicação em: 4 DEZEMBRO 2020 